\title{
Antiobesity and Cholesterol-Lowering Effects of Bifidobacteria animalis DY-64 in Rats Fed a High-Fat/High-Cholesterol Diet
}

\author{
Seong-Ho Choi ${ }^{1,2}$, Myung-Yul Lee, Deok-Young Jhon ${ }^{3}$, Yang-II Choi ${ }^{1}$, and Jae-Joon Lee* \\ Department of Food and Nutrition, Chosun University, Gwangju 500-759, Korea \\ ${ }^{1}$ Department of Animal Science, Chungbuk National University, Cheongju 361-763, Korea \\ ${ }^{2}$ Department of Animal Science, Texas A\&M University, College Station, TX 77843, USA \\ ${ }^{3}$ Department of Food and Nutrition, Chonnam National University, Gwangju 550-757, Korea
}

\begin{abstract}
The present study was carried out to investigate the antiobesity and hypocholesterolemic effects of Bifidobacteria animalis DY-64 (B. animalis DY-64), a lactic acid bacterium isolated from the human intestine, in rats fed a high-fat/high-cholesterol diet for 4 weeks. Forty male Sprague-Dawley rats were divided into four groups and fed either a normal $(\mathrm{N})$ or highfat/high-cholesterol (HFC) diet without or with oral administration of B. animalis DY-64 (N-BA, HFC-BA). The gain in body weight, and liver and adipose tissue weights of the HFC group were heavier than that of the HFC-BA group. Serum total cholesterol (TC), LDL-cholesterol, and leptin levels of the HFC group, which were significantly elevated compared to those of the N group, dropped by 19,18,21, and 13\% in the HFC-BA group, respectively, whereas the serum HDL-cholesterol level markedly increased. However, serum TG, LDL-cholesterol, HDL-cholesterol, and leptin levels were not significantly different among the $\mathrm{N}$ groups (N, N-BA) with or without B. animalis DY-64 administration. TC and TG levels of the liver as well as the TG level of the adipose tissue were significantly reduced in the HFC-BA group. In addition, HR-LPL activity in adipose tissue was also lower in the HFC-BA group than in the HFC group. These results suggest that $B$. animalis DY-64 isolated from the human intestine exerts hypocholesterolemic effects by reducing serum and liver cholesterol levels and plays a role in the prevention of obesity induced by HFC diet.
\end{abstract}

Key words: Bifidobacteria animalis DY-64, high-fat/high-cholesterol diet, obesity, cholesterol, rat

\section{Introduction}

Obesity, a condition in which an abnormally large amount of fat is stored as adipose tissue, is becoming a global epidemic as well as a major contributor to the increased incidence of serious chronic diseases such as type 2 diabetes, cardiovascular diseases, hepatic and skeletal muscle insulin resistance, hypertension, arthritis, and certain forms of cancer (Haslam, 2005). In general, it is known that a high-fat diet contributes to obesity, and long-term intake evokes significant increases in abdominal fat weights in mammals (Iwashita et al., 2002). Since obesity and cardiovascular disease are prevalent health problems worldwide, researchers have become interested in the effectiveness of different foods in reducing body

*Corresponding author: Jae-Joon Lee, Department of Food and Nutrition, Chosun University, Gwangju 500-759, Korea. Tel: 82-62-230-7725, Fax: 82-62-234-7452, E-mail: leejj80@chosun.ac.kr weight and improving other risk factors (Nettleton et al., 2009; Nicolosi et al., 2001).

Probiotics such as lactic acid bacteria (LAB) are known to exert various physiological functions in humans. Recent studies have reported the preventive effects of probiotics on obesity and cardiovascular diseases such as atherosclerosis, coronary heart diseases, and stroke (An et al., 2011; Xiao et al., 2010). Among commensal bacteria, Bifidobacterium, which belongs to Actinomycetes and is also a kind of LAB, is one of the most prolific probiotics in the mammalian gut (An et al., 2011; Yin et al., 2010). Bifidobacterium and Lactobacillus have been used in fermented foods for several centuries without any adverse effects (Fuller, 1992), and they are classified as Generally Recognized as Safe (GRAS) due to their long history of safe use, particularly in dairy foods (Donohu, 2006). Xiao et al (2003) previously observed that a strain of Bifidobacterium longum exhibited more significant effects in lowering serum total cholesterol than a mixed culture of 
Streptococcus thermophilus and Lactobacillus delbrueckii subspecies in both rats and humans. Furthermore, several studies have reported antiobesity effects of bacterial strains such as Bifidobacterium and Lactobacillus (An et al., 2011; Yin et al., 2010). An et al (2011) found that Bifidobacterium spp. has hypocholsterolemic and hypotriacylglycerolemic effects in high fat diet-induced obese rats. Further, Bifidobacterium spp. has been observed to reduce body weight in rats. Thus, Bifidobacterium appears to improve lipid metabolism and body fat deposition.

The antiobesity and hypocholesterolemic effects of LAB have become an area of great interest and controversy for many researchers. In this study, we evaluated the effects of $B$. animalis DY-64 isolated from the human intestine on obesity based on body weight, feed intake, serum leptin and lipid levels, and adipose tissue LPL activity in high-fat/high-cholesterol diet-induced rats. It is known that high-fat/high-cholesterol diet-induced animal models can develop obesity, hyperglycemia, hypercholesterolemia, and hyperinsulinemia (Garrow et al., 1992).

\section{Material and Methods}

\section{Animal and diets}

A total of 32 male Sprague-Dawley rats, initial body weight $150 \mathrm{~g}$, were purchased from Central Lab Animal Inc. (Korea) at 4 wk of age. Rats were housed in individual stainless steel cages under controlled conditions at temperatures between 21 and $23^{\circ} \mathrm{C}$ with a $12: 12 \mathrm{~h}$ lightdark cycle (08:00-20:00 h light). Rats were provided unrestricted access to rat chow and water in our animal facility for at least $2 \mathrm{wk}$ before the experiments in order to minimize the effects of changes in feeding schedules and diurnal rhythms on data variability. As shown in Table 1, four experimental groups were normal $\operatorname{diet}(\mathrm{N})$, normal diet with $B$. animalis DY-64 (N-BA), high-fat/ high-cholesterol diet (HFC), and high-fat/high-cholesterol diet with $B$. animalis DY-64 (HFC-BA). Animal diets were formulated based on AIN-93 (Reeves et al., 1993). Rats had free access to water and their group-specific diet. B. animalis DY-64 provided by Professor D. Y. Jhon (Chonnam National University, Korea) was supplied as a freeze-dried powder in sealed packets containing about $2 \times 10^{11} \mathrm{CFU} / \mathrm{g}$ until dissolved in sterilized phosphate buffer (PBS) for use. Rats were orally administered 0.5 $\mathrm{mL}$ of sterilized PBS or $10^{9} \mathrm{CFU}$ of $B$. animalis DY-64 per day for 4 wk. Feed intake and body weight were measured weekly. This animal experiment was performed according to the guidelines of the Animal Use Committee
Table 1. Composition of experimental diet (g/kg diet)

\begin{tabular}{ccc}
\hline \hline Ingredients & $\mathrm{N}$ & HFC \\
\hline Casein & 200.0 & 200.0 \\
L-cystine & 1.8 & 1.8 \\
Corn starch & 501.2 & 391.2 \\
Sucrose & 100.0 & 100.0 \\
Cellulose & 50.0 & 50.0 \\
Lard & 100.0 & 200.0 \\
Mineral mix ${ }^{1)}$ & 35.0 & 35.0 \\
Vitamin mix & & 10.0 \\
Choline bitartate & 10.0 & 2.0 \\
Cholesterol & 2.0 & 10.0 \\
\hline
\end{tabular}

${ }^{1,2)}$ AIN-93-MX mineral mixture and AIN-93-VX vitamin mixture (Reeves et al., 1993).

of Chosun University.

\section{Measurement of organ weights as well as serum lipid and leptin levels}

At the end of the experimental period, experimental diets were withheld for $12 \mathrm{~h}$. On the day of an experiment, rats were killed by decapitation after light anesthesia in a $\mathrm{CO}_{2}$-saturated chamber, and blood samples from each rat were collected into tubes. Sera were separated from blood by centrifugation at 3,000 rpm for $20 \mathrm{~min}$. After bleeding, liver, epididymal, and mesenteric adipose tissues were quickly excised, weighed, and frozen in liquid nitrogen for subsequent analysis. Serum concentrations of triglyceride (TG), total cholesterol (TC), and high-density lipoprotein cholesterol (HDL-cholesterol) were calculated using a commercial assay kit (Fuji Dri-Chem 3500s, Fujifilm, Japan). Serum low-density lipoprotein cholesterol (LDL-cholesterol) was calculated by the Friedwald formula (Friedwald et al., 1972) \{total cholesterol - (HDLcholesterol-TG/5)\}. The atherogenic index (AI) and cardiac risk factor (CRF) were calculated using the following formulas: (total cholesterol - HDL-cholesterol)/ HDL-cholesterol\} and \{total-cholesterol/HDL-choleterol\}, respectively (Rosenfeld, 1989). An enzyme-linked immunosorbent assay kit (Linco Research, USA) was used to determine serum leptin levels, according to the manufacturer's instructions. The absorbance was measured using a microplate spectrophotometer (Biorad, USA).

\section{Measurement of TG and TC concentrations in liver and adipose tissues}

Liver, epididymal, and mesenteric adipose tissues lipids were extracted by the Folch method (Folch et al., 1957). Extracted lipids were then divided into subsamples of 500 $\mu \mathrm{L}$ each after weighing. TG and TC contents in liver and 
adipose tissues were measured by the methods of Biggs et al. (1975), and Zlatkis and Zak (1969), respectively.

\section{Assay of lipoprotein lipase (LPL) activity}

LPL activity was measured according to the method of Nilsson-Ehle and Schotz (1976). Dissected epididymal and mesenteric adipose tissues were minced into 5-10 $\mathrm{mg}$ fragments totaling $50 \mathrm{mg}$ and frozen in liquid nitrogen. To assess heparin-releasable LPL (HR-LPL) activity, tissue fragments were defrosted in $0.4 \mathrm{~mL}$ of Medium 199 (Gibco BRL, USA) containing 1\% bovine serum albumin and $50 \mathrm{U} / \mathrm{mL}$ of heparin, followed by incu- bation for $45 \mathrm{~min}$ at $24^{\circ} \mathrm{C}$ with shaking. LPL activity in the heparin elute was measured using the glycerol stabilized ${ }^{3} \mathrm{H}$-triolein emulsion as substrate. One unit of LPL activity is defined as the release of $1 \mu \mathrm{mol}$ of free fatty acid in $1 \mathrm{~h}$.

\section{Statistical analysis}

All data were expressed as the means \pm standard error of mean (SEM). Statistical analysis was performed using ANOVA followed by Tukey's test. Student's t-test was used to confirm comparisons between the groups. Statistical significance was considered to be at the $p<0.05$ level.

\section{Results and Discussion}

\section{Effects of BA on body weight gain, feed intake, and feed efficiency ratio}

All rats appeared to be healthy, showing no pathological signs or abnormalities during the administration period. Daily body weight gain, feed intake, and feed efficiency ratio (FER) are shown in Table 2. In general, changes in body weight reflect the overall effects of antiobesity candidate materials in vivo. Body weight gain, feed intake, and FER did not differ among the $\mathrm{N}$ groups (N, N-BA), whereas the HFC group had slightly exhibited higher body weight. The HCF group had showed a $+22 \%$ increase in body weight compared to the $\mathrm{N}$ group. In contrast, the HFC-BA group had showed a significantly lower body weight gain of $-17 \%$ compared to the $\mathrm{HCF}$ group. This reduction of body weight of the HFC-BA group was comparable to that of the $\mathrm{N}$ group, suggesting that $B$. animalis DY-64 administration was able to retard increases in body weight. Feed intake of the HCF group was lower

Table 2. Effects of $B$. animalis DY-64 administration on body weight gain, feed intake and feed efficiency ratio, liver and adipose tissue weights in rats fed high-fat/high-cholesterol diet

\begin{tabular}{|c|c|c|c|c|c|c|}
\hline \multirow{2}{*}{ Groups $^{1)}$} & Body weight gain & Feed intake & \multirow{2}{*}{ FER $^{2)}$} & Liver & Mesenteric $\mathrm{AT}^{3)}$ & Epididymal AT \\
\hline & \multicolumn{2}{|c|}{ (g/day) } & & \multicolumn{3}{|c|}{ (g/100 g body wt.) } \\
\hline $\mathrm{N}$ & $5.63 \pm 0.52^{4) b 5)}$ & $26.20 \pm 1.37^{\mathrm{a}}$ & $0.22 \pm 0.03^{\mathrm{c}}$ & $3.42 \pm 0.41^{\mathrm{c}}$ & $0.97 \pm 0.26^{\mathrm{b}}$ & $2.81 \pm 0.13^{b}$ \\
\hline N-BA & $5.44 \pm 0.23^{\mathrm{b}}$ & $26.54 \pm 2.14^{\mathrm{a}}$ & $0.21 \pm 0.04^{\mathrm{c}}$ & $3.38 \pm 0.38^{\mathrm{c}}$ & $0.91 \pm 0.19^{b}$ & $1.98 \pm 0.29^{\mathrm{b}}$ \\
\hline $\mathrm{HFC}$ & $7.22 \pm 0.54^{\mathrm{a}}$ & $22.34 \pm 1.80^{\mathrm{b}}$ & $0.32 \pm 0.06^{\mathrm{a}}$ & $5.17 \pm 0.84^{\mathrm{a}}$ & $1.94 \pm 0.22^{\mathrm{a}}$ & $2.98 \pm 0.58^{\mathrm{a}}$ \\
\hline HFC-BA & $6.01 \pm 0.37^{b}$ & $22.21 \pm 1.02^{b}$ & $0.27 \pm 0.02^{b}$ & $4.07 \pm 0.70^{\mathrm{b}}$ & $1.02 \pm 0.17^{\mathrm{b}}$ & $2.31 \pm 0.35^{\mathrm{ab}}$ \\
\hline
\end{tabular}

${ }^{1)}$ Groups were as follow: N, normal diet; N-BA, normal diet $+B$. animalis DY-64 administration; HFC, high-fat/high-cholesterol diet; HFC-BA, high-fat/high-cholesterol diet $+B$. animalis DY-64 administration.

${ }^{2)}$ FER (feed efficiency ratio): weight gain (g/day) / feed intake (g/day).

${ }^{3)}$ AT: adipose tissue.

${ }^{4)}$ The results are mean \pm S.E. for eight rats in each group.

${ }^{5}$ Values with different superscripts in the same column are significantly different $(p<0.05)$ between groups by Tukey's test.

Table 3. Effects of $B$. animalis DY-64 administration on triglyceride and total cholesterol contents in serum of rats fed high-fat/ high-cholesterol diet

\begin{tabular}{|c|c|c|c|c|c|c|}
\hline \multirow{2}{*}{ Groups $^{1)}$} & Triglyceride & Total cholesterol & LDL-cholesterol $^{2)}$ & HDL-cholesterol & \multirow{2}{*}{$\mathrm{CRF}^{3)}$} & \multirow{2}{*}{$\mathrm{AI}^{4)}$} \\
\hline & \multicolumn{4}{|c|}{$(\mathrm{mg} / \mathrm{dL})$} & & \\
\hline $\mathrm{N}$ & $65.41 \pm 5.02^{5) b c 6)}$ & $87.97 \pm 4.23^{b}$ & $64.87 \pm 4.29^{\mathrm{b}}$ & $50.23 \pm 4.19^{\mathrm{a}}$ & $1.75 \pm 0.10^{b}$ & $0.75 \pm 0.04^{b}$ \\
\hline N-BA & $60.36 \pm 7.98^{c}$ & $82.34 \pm 6.17^{b}$ & $59.80 \pm 3.79^{\mathrm{b}}$ & $52.36 \pm 5.12^{\mathrm{a}}$ & $1.57 \pm 0.06^{\mathrm{bc}}$ & $0.57 \pm 0.05^{\mathrm{bc}}$ \\
\hline HFC & $89.14 \pm 6.27^{\mathrm{a}}$ & $109.28 \pm 9.36^{\mathrm{a}}$ & $83.99 \pm 5.78^{a}$ & $32.29 \pm 2.36^{\mathrm{c}}$ & $3.38 \pm 0.06^{\mathrm{a}}$ & $2.38 \pm 0.02^{\mathrm{a}}$ \\
\hline HFC-BA & $72.02 \pm 5.74^{b}$ & $89.23 \pm 7.23^{\mathrm{b}}$ & $66.42 \pm 4.20^{\mathrm{b}}$ & $42.02 \pm 5.01^{\mathrm{b}}$ & $2.12 \pm 0.05^{\mathrm{b}}$ & $1.12 \pm 0.06^{\mathrm{b}}$ \\
\hline
\end{tabular}

${ }^{1)}$ Groups were as follow: N, normal diet; N-BA, normal diet $+B$. animalis DY-64 administration; HFC, high-fat/high-cholesterol diet; HFC-BA, high-fat/high-cholesterol diet $+B$. animalis DY-64 administration.

${ }^{2)} \mathrm{LDL}$ cholesterol $=\{$ total cholesterol $-(\mathrm{HDL}-$ cholesterol + triglyceride $/ 5)\}$.

${ }^{3)} \mathrm{CRF}$ (cardiac risk factor) $=$ total cholesterol / HDL - cholesterol.

4) $\mathrm{AI}$ (atherosclerotic index $)=($ total cholesterol $-\mathrm{HDL}-$ cholesterol $) / \mathrm{HDL}-$ cholesterol.

${ }^{5)}$ The results are mean \pm S.E. for eight rats in each group.

${ }^{6)}$ Values with different superscripts in the same column are significantly different $(p<0.05)$ between groups by Tukey's test. 
than that of the $\mathrm{N}$ group, but it did not differ between the HFC and HFC-BA groups. In the present study, body weight gain of the HFC group was successfully prevented by $B$. animalis DY-64 administration without any alteration of feed intake. FER was higher in the HFC groups (HFC, HFC-BA) than in the $\mathrm{N}$ groups (N, N-BA).

\section{Weights of adipose tissue and liver}

As shown in Table 2, weights of white adipose tissues, including epididymal and mesenteric adipose tissues, were elevated in the HFC groups relative to the $\mathrm{N}$ groups. Compared with the HFC group, the HFC-BA group had slightly decreased epididymal adipose tissue weight. In relation to this, Lee et al, (2007) has also observed that Lactobacillus plantarum PL62 reduced weights of epididymal, inguinal, mesenteric, and perirenal white adipose tissues and significantly reduced body weights in diet-induced obese mice. However, in the $\mathrm{N}$ groups $(\mathrm{N}, \mathrm{NB})$ with or without B. animalis DY-64 administration, weights of adipose tissues were not significantly different among the groups. The effects of diet or $B$. animalis DY-64 administration on adipose tissues weights corresponded with changes in weight gain. These findings were in agreement with previous studies (Lee et al., 2006; Lee et al., 2007).

Liver weights were significantly higher in the HFC groups than in the $\mathrm{N}$ groups (Table 2). B. animalis DY-64 administration reduced liver weight only in the HFC group. There was no significant effect of $B$. animalis DY-64 administration on liver weight in the $\mathrm{N}$ groups.

\section{Serum leptin contents}

Leptin has been identified as an antiobesity hormone that regulates body weight by controlling food intake and energy expenditure via the hypothalamic-pituitary-gonadal axis (Friedman, 2002). Therefore, leptin may be an important factor in obesity management. Serum leptin contents are shown in Fig. 1. Leptin contents in serum were higher in the HFC groups than in the $\mathrm{N}$ groups. However, leptin content of the HFC-BA group was significantly reduced compared with that that of the HFC group. Similar results have been observed in other studies using rats (An et al., 2011), mice (Lee et al., 2006), and humans (Considine et al., 1996). These results suggest that reduction of white adipose tissue and body weights is associated with reduction of leptin. There were no differences in the contents of serum leptin between the $\mathrm{N}$ groups.

\section{Serum lipid contents}

Serum TG, TC, LDL-cholesterol, HDL-cholesterol, athe-

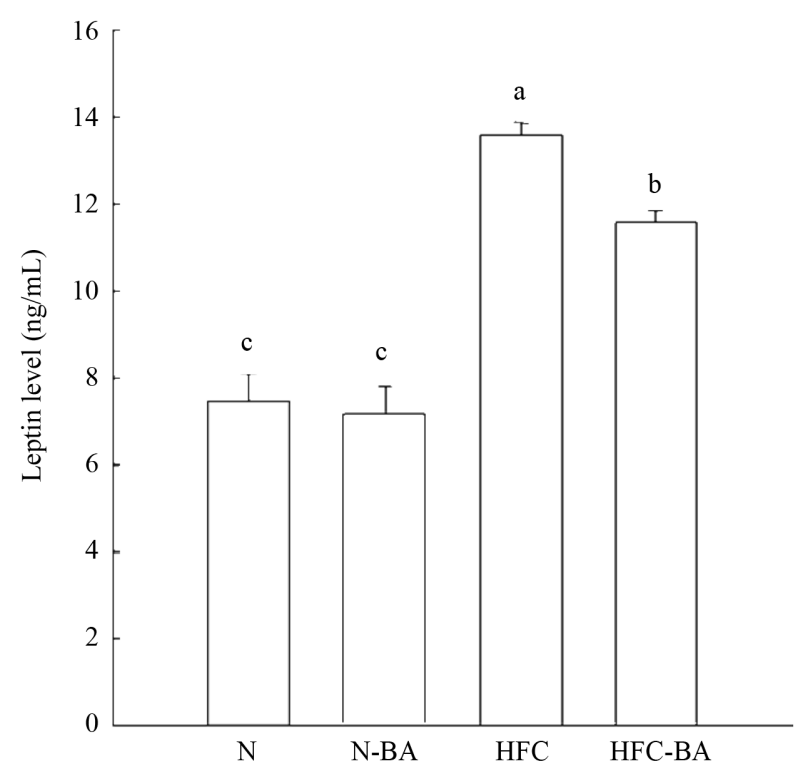

Fig. 1. Effects of $B$. animalis DY-64 administration on serum leptin levels in rats fed high-fat/high-cholesterol diet. ${ }^{1)}$ Groups were as follow: N, normal diet; N-BA, normal diet $+B$. animalis DY-64 administration; HFC, High-fat/ High-cholesterol diet; HFC-BA, High-fat/High-cholesterol $\operatorname{diet}+B$. animalis DY-64 administration. The results are mean \pm S.E. for eight rats in each group, and different superscript letters indicate significant differences at $p<0.05$ by Tukey's test.

rogenic index (AI), and cardiac risk factor (CRF) in each group are presented in Table 3. Compared with the HFC group, the HFC-BA group showed reduced TG, TC, and LDL-cholesterol contents. The HFC-BA group had showed $19 \%$ lower serum TG as well as $18 \%$ lower serum TC contents compared to the HFC group. Oral administration of $B$. animalis DY-64 reduced the serum TC level in rats without any pathogenic side effects. However, among the $\mathrm{N}$ groups with or without $B$. animalis DY-64 administration, serum TG, TC, LDL-cholesterol, and HDL-cholesterol levels were not significantly different. The concentration of serum LDL-cholesterol declined by $21 \%$ in the HFC-BA group compared with the HFC group. Further, there was a significant increase in the $\mathrm{AI}$ and $\mathrm{CRF}$ of the HFC group compared with the $\mathrm{N}$ group, whereas the AI and CRF fell significantly in the HFC-BA group compared with the HFC group. These findings were in agreement with previous studies (Lee et al., 2009; Xie et al., 2011). LDL-cholesterol is the main component of serum cholesterol. Therefore, lowering of the LDL-cholesterol level may be an important factor for reducing serum TC. Reduction of LDL-cholesterol and TG in serum is reported to lower the risk of coronary heart disease (Taylor and Williams, 1998). Our LAB strain attenuated the 
Table 4. Effects of $B$. animalis DY-64 administration on triglyceride and total cholesterol contents in liver of rats fed high-fat/high-cholesterol diet

\begin{tabular}{|c|c|c|}
\hline \multirow{2}{*}{ Groups $^{1)}$} & Triglyceride & Total cholesterol \\
\hline & \multicolumn{2}{|c|}{$(\mathrm{mg} / \mathrm{g}$, wet weight $)$} \\
\hline $\mathrm{N}$ & $19.24 \pm 0.31^{2) b 3)}$ & $5.64 \pm 0.14^{b}$ \\
\hline N-BA & $20.13 \pm 0.54^{\mathrm{a}}$ & $3.99 \pm 0.42^{\mathrm{c}}$ \\
\hline HFC & $31.87 \pm 0.45^{\mathrm{a}}$ & $9.54 \pm 0.28^{\mathrm{ab}}$ \\
\hline HFC-BA & $24.20 \pm 0.87^{\mathrm{b}}$ & $6.23 \pm 0.52^{\mathrm{b}}$ \\
\hline
\end{tabular}

${ }^{1)}$ Groups were as follow: N, normal diet; N-BA, normal diet $+B$. animalis DY-64 administration; HFC, high-fat/high-cholesterol diet; HFC-BA, high-fat/high-cholesterol diet + B. animalis DY-64 administration.

${ }^{2)}$ The results are mean \pm S.E. for eight rats in each group.

${ }^{3)}$ Values with different superscripts in the same column are significantly different $(p<0.05)$ between groups by Tukey's test.

increases in serum LDL-cholesterol in rats caused by the HFC group compared to the $\mathrm{N}$ group. The present results further show that B. animalis DY-64 reduced serum TG, TC, LDL-cholesterol, AI, and CRF in rats fed HFC diet.

\section{Lipid contents in liver and adipose tissues}

The effects of HFC diet and B. animalis DY-64 administration on TG and TC contents in liver and adipose tissues are shown in Tables 4 and 5. Table 4 shows the changes in liver lipids after administration of $B$. animalis DY-64. Similar to serum levels, liver TG and TC levels were significantly reduced by 25 and $35 \%$, respectively, in the HFC-BA group compared to the HFC group. On the other hand, there were no significant differences in liver $\mathrm{TG}$ and $\mathrm{TC}$ contents among the $\mathrm{N}$ groups with or without $B$. animalis DY-64 administration.

TC levels in adipose tissues were not significantly different between the $\mathrm{N}$ group and the HFC group (Table 5). TG level in adipose tissue was significantly higher in the HFC groups than in the $\mathrm{N}$ groups. However, among the $\mathrm{N}$
Table 6. Effects of $B$. animalis DY-64 administration on HRLPL activity in adipose tissues of rats fed high-fat/ high-cholesterol diet

\begin{tabular}{ccc}
\hline \hline \multirow{2}{*}{ Groups $^{1)}$} & Mesenteric AT & Epididymal AT \\
\cline { 2 - 3 } & \multicolumn{2}{c}{ HR-LPL activity ${ }^{2}($ Unit $/ \mathrm{g})$} \\
\hline N & $3.42 \pm 0.29^{\left.3 \mathrm{~b}^{\mathrm{b}}\right)}$ & $14.64 \pm 1.92^{\mathrm{b}}$ \\
N-BA & $3.02 \pm 0.48^{\mathrm{b}}$ & $14.11 \pm 2.43^{\mathrm{b}}$ \\
HFC & $5.01 \pm 0.51^{\mathrm{a}}$ & $20.29 \pm 3.21^{\mathrm{a}}$ \\
HFC-BA & $3.98 \pm 0.38^{\mathrm{b}}$ & $15.01 \pm 1.48^{\mathrm{b}}$ \\
\hline
\end{tabular}

${ }^{1)}$ Groups were as follow: N, normal diet; N-BA, normal diet $+B$. animalis DY-64 administration; HFC, high-fat/high-cholesterol diet; HFC-BA, high-fat/high-cholesterol diet + B. animalis DY-64 administration.

${ }^{2}$ Heparin-releasable lipoprotein (HR-LPL) activity was measured in media samples after incubation of epididymal and mesenteric white adipose tissue fragments with $5 \times 10^{3}$ units/L of heparin for $45 \mathrm{~min}$ at $24^{\circ} \mathrm{C}$.

${ }^{3)}$ The results are mean \pm S.E. for eight rats in each group.

${ }^{4)}$ Values with different superscripts in the same column are significantly different $(p<0.05)$ between groups by Tukey's test.

groups with or without $B$. animalis DY-64 administration, adipose tissue TG and TC levels were not significantly different. However, adipose tissue TG content in the HFCBA group was significantly reduced compared to the HFC group.

\section{LPL activity in adipose tissues}

LPL is an enzyme responsible for the hydrolysis of triglycerides from plasma lipoproteins, mainly chylomicron and VLDL, and its activity is influenced by nutritional and hormonal status as well as environmental conditions (Eckel, 1989). Further, LPL is a factor that contributes to the development of obesity (Fried et al., 1989). LPL activity is markedly elevated in adipose tissue of genetically obese rodents (Fried et al., 1989) as well as in obese humans (Ong and Kern, 1989). LPL activities in epididymal and mesenteric adipose tissues were significantly higher

Table 5. Effects of $B$. animalis DY-64 administration on triglyceride and total cholesterol contents in adipose tissues of rats fed high-fat/high-cholesterol diet

\begin{tabular}{|c|c|c|c|c|}
\hline \multirow{3}{*}{ Group $^{1)}$} & \multicolumn{2}{|c|}{ Mesenteric $\mathrm{AT}^{21}$} & \multicolumn{2}{|c|}{ Epididymal AT } \\
\hline & Triglyceride & Total cholesterol & Triglyceride & Total cholesterol \\
\hline & \multicolumn{2}{|c|}{ (mg/g, wet weight $)$} & \multicolumn{2}{|c|}{ (mg/g, wet weight) } \\
\hline $\mathrm{N}$ & $317.51 \pm 19.34^{3) \text { ab4) }}$ & $30.14 \pm 2.09^{\mathrm{NS5})}$ & $466.55 \pm 21.33^{\mathrm{c}}$ & $26.42 \pm 2.42^{\mathrm{NS}}$ \\
\hline N-BA & $328.74 \pm 31.299^{\mathrm{a}}$ & $32.11 \pm 3.48$ & $488.26 \pm 19.87^{\mathrm{a}}$ & $25.98 \pm 3.23$ \\
\hline HFC & $401.61 \pm 21.24^{\mathrm{ab}}$ & $34.92 \pm 2.33$ & $677.29 \pm 35.69^{b}$ & $29.21 \pm 3.40$ \\
\hline HFC-BA & $362.11 \pm 33.42^{\mathrm{b}}$ & $32.64 \pm 1.98$ & $526.32 \pm 21.33^{\mathrm{b}}$ & $26.14 \pm 2.87$ \\
\hline
\end{tabular}

${ }^{1)}$ Groups were as follow: N, normal diet; N-BA, normal diet + B. animalis DY-64 administration; HFC, high-fat/high-cholesterol diet; HFC-BA, high-fat/high-cholesterol diet $+B$. animalis DY-64 administration.

${ }^{2)}$ AT: adipose tissue.

${ }^{3)}$ The results are mean $\pm \mathrm{SE}$ for eight rats in each group.

${ }^{4)}$ Values with different superscripts in the same column are significantly different $(p<0.05)$ among groups by Tukey's test.

${ }^{5)} \mathrm{NS}$ : not significantly different among groups. 
in the HFC group than in the N group (Table 6). LPL is likely to reduce hyperlipidemia induced by consumption of HFC diet. The HFC-BA group had significantly lowered LPL activity in adipose tissues compared to the HFC group. Cruz and Williamson (1992) reported that there is a close correlation between LPL activities in adipose tissue of rats and transportation of triglycerides to adipose tissue, and LPL regulates the accumulation of fat in adipose tissue. Further, LPL activity in mesenteric adipose tissue was lower than that in epididymal adipose tissue.

In the present study, B. animalis DY-64 administration to HFC diet-induced obese rats reduced body weight gain, inhibited adipose tissue accumulation, and reduced LPL activity in adipose tissue. B. animalis DY-64 administration to HFC diet-induced obese rats also reduced serum leptin, TG, and TC contents. These results indicate that $B$. animalis DY-64 has potent anti-obesity and hypolipidemic effects.

\section{Acknowledgements}

This study was supported by the research fund of Chosun University, 2012.

\section{References}

1. An, H. M., Park, S. Y., Lee, D. K., Kim, J. R., Cha, M. K., Lee, S. W., Lim, H. T., Kim, K. J., and Ha, N. J. (2011) Antiobesity and lipid-lowering effects of Bifidobacterium spp. in high fat diet-induced obese rats. Lipids Health Dis. 10, 116124.

2. Biggs, H. G., Erikson, T. M., and Moorehead, W. R. (1975) A manual colorimetric assay of triglyceride in serum. Clin. Chem. 21, 437-441.

3. Considine, R. V., Shinha, M. K., and Heiman, M. L. (1996) Serum immunoreactive leptin concentrations in normal weight and obese humans. New Engl. J. Med. 334, 292-295.

4. Cruz, M. L. and Williamson, D. H. (1992) Refeeding meal-fed rats increased lipoprotein lipase activity and deposition of dietary $\left[{ }^{14} \mathrm{C}\right]$ lipid in white adipose tissue and decrease oxidation to ${ }^{14} \mathrm{CO}_{2}$. Biochem. J. 285, 773-778.

5. Donohue, D. C. (2006) Safety of probiotics. Asia. Pac. J. Clin. Nutr. 15, 563-569.

6. Eckel, R. H. (1989) Lipoprotein lipase: A multifunctional enzyme relevant to common metabolic disease. New Eng. J. Med. 320, 1060-1068.

7. Folch, J., Lees, M., and Sloane-Stanley, G. (1957) A simple method for the isolation and purification of total lipids from animal tissues. J. Biol. Chem. 226, 497-509.

8. Fried, S. K., Turkenkopf, I. J., Goldberg, I. J., Doolittle, M. H., Kirchgessner, T. G., Schotz, M. C., Johnson, P. R., and Greenwood, M. R. C. (1991) Mechanisms of increased lipo- protein lipase in fat cells of obese Zucker rats. Am. J. Physiol. 261, E653-E660.

9. Friedman, J. M. (2002) The function of leptin in nutrition, weight, and physiology. Nutr. Rev. 60, S1-S14.

10. Friedwald, W., Levy, R., and Fredrickson, D. (1972) Estimation of the concentration of low-density lipoprotein cholesterol in plasma, without use of the preparative ultracentrifuge. Clin. Chem. 18, 499-502.

11. Fuller, R. (1992) History and development of probiotics. Probiotics-The Scientific Basis Champman and Hall, London: Fukker, R. 1-18.

12. Garrow, J. S. (1992) Treatment of obesity. Lancet 340, 409413.

13. Haslam, D. W. (2005) Obesity. Lancet 366, 1197-1209.

14. Iwashita, S., Tandia, M., Terui, N., Ootsuka, Y., Shu, M., Kang, D. (2002) Direct measurement of renal sympathetic nervous activity in high-fat diet-related hypertensive rats. Life Sci. 71, 537-546.

15. Lee, D. K., Jang, S., Baek, E. H., Kim, M. J., Lee, K. S., Shin, H. S., Chung, M. J., Kim, J. E., Lee, K. O., and Ha, N. J. (2009) Lactic acid bacteria affect serum cholesterol levels, harmful enzyme activity, and fecal water content. Lipids Health Dis. 8, 21-19.

16. Lee, H. Y., Park, J. H., Seok, S. H., Baek, M. W., Kim, D. J., Lee, K. E., Paek, K. S., Lee, Y. H., and Park, J. H. (2006) Human originated bacteria, Lactobacillus rhamnous PL60, produce conjugated linoleic acid and show anti-obesity effects in diet-induced obese mice. Biochim. Biophys, Acta. 1761, 736-744.

17. Lee, K., Paek, K., Lee, Y. H., Park, J. H., and Lee, Y. (2007) Antiobesity effect trans-10,cis-12-conjugated linoleic acidproducing Lactobacillus planetarium PL62 on diet-induced obese mice. J. Appl. Microbiol. 103, 1140-1146.

18. Nettleton, J. A., Polak, J. F., Tracy, R., Burke, G. L., and Jacobs Jr, D. R. (2009) Dietary patterns and incident cardiovascular disease in the multi-ethnic study of atherosclerosis. Am. J. Clin. Nutr. 90, 647-654.

19. Nicolosi, R. J., Wilson, T. A., Lawton, C., and Handelman, G. J. (2001) Dietary effects on cardiovascular disease risk factors: beyond saturated fatty acids and cholesterol. J. Am. Coll. Nutr. 20, 421-427.

20. Nilsson-Ehle, P and Schotz, M. A. (1976). A stable, radioactive substrate emulsion for assay of lipoprotein lipase. J. Lipid Res. 17, 536-541.

21. Reeves, P. G., Nielson, F. H., and Fahey Jr, G C. (1993) AIN93 purified diets for laboratory rodents: Final report of the American Institute of Nutrition adhoc writing committee on the reformulation of the AIN-76A rodent diet. J. Nutr. 123, 1939-1951.

22. Ong, Z. M. and Kern, P. A. (1989) Effect of feeding and obesity on lipoprotein lipase activity, immunoreactive protein, and messenger RNA levels in human adipose tissue. J. Clin. Invest. 84, 305-311.

23. Rosenfeld, L. (1989) Lipoprotein analysis. Arch. Pathol. Lab. Med. 113, 1101-1110.

24. Taylor, G. R. J. and Williams, C. M. (1998) Effects of probi- 
otics and prebiotics on blood lipids. Br. J. Nutr. 80, S225-S230.

25. Xiao, J. Z., Kondo, S., Takahashi, N., Oshida, K., Hiramatsu, A., Iwatsuki, K., Kobubo, S., and Hosono, A. (2003) Effects of milk products fermented by Bifidibaterium longum on blood lipids in rats and healthy adult male volunteers. J. Dairy Sci. 86, 2452-2461.

26. Xie, N., Cui, Y. N., Zhao, X., Yang, Z. W., Wang, Z. G., Fu, N., Tang, Y., Wang, X. H., Liu, X. W., Wang, C. L., Lu, F. G. (2011) Effects of two Lactobacillus strains on lipid metabo- lism and intestinal microflora in rats fed a high-cholesterol diet. BMC Complemetary Alternative Med. 11, 53-63.

27. Yin, Y. N., Yu, Q. F., Fu, N., Liu, X. W., and Lu, F. G. (2010) Effects of four Bifidobacteria on obesity in high-fat diet induced rats. World J. Gastroenterol. 16, 3394-401.

28. Zlatkis, A. and Zak, B. (1969) Study of a new cholesterol reagent. Anal. Biochem. 29, 143-148.

$\overline{\text { (Received 2013.5.6/Revised 2013.10.21/Accepted 2013.10.21) }}$ 